\title{
The German Version of the Veterans Rand - 36/12 Item Health Survey: Translation and Adaptation of a Generic Health Assessment Instrument in a Sample of Inpatient Rehabilitation Patients
}

\section{Ines Buchholz}

German Statutory Insurance https://orcid.org/0000-0001-9729-6992

\section{You-Shan Feng}

University Hospitals Tubingen: Universitatsklinikum Tubingen

Maresa Buchholz

University Medicine Greifswald

Lewis E. Kazis

BUSPH: Boston University School of Public Health

Thomas Kohlmann ( $\square$ thomas.kohlmann@med.uni-greifswald.de)

University Medicine Greifswald https://orcid.org/0000-0002-5956-8309

\section{Research}

Keywords: Health Survey, psychosomatic , orthopedic

Posted Date: November 2nd, 2020

DOI: https://doi.org/10.21203/rs.3.rs-98587/v1

License: (c) (i) This work is licensed under a Creative Commons Attribution 4.0 International License.

Read Full License 
Health related quality of life (HRQoL) is a crucial outcome metric used in settings from clinical trials [1-2] to population health surveillance [3-7]. The Veterans Rand questionnaire (VR) is a multi-attribute generic instrument measuring patient-reported HRQoL. The instrument has a long (VR-36) and a short form (VR-12), both measuring a physical component summary $\left(\mathrm{PCS}_{\mathrm{VR}}\right)$ and a mental component summary $\left(\mathrm{MCS}_{\mathrm{VR}}\right)$. The VR-36 also is comprised of eight scales, which correspond closely to the Medical Outcome Study (MOS) Short Form 36 version 1.0 (SF-36, [8-10]).

The VR instruments were created to address the veteran population in the United States (US) [11]. The Veterans Health Administration (VHA) is a national health care system, which serves over nine million military veterans in the US. It is one of the largest integrated health care systems in the US. This patient population has special medical needs, is older, poorer, sicker (with more diseases than veterans nationally) and has a higher percentage of men than the general adult population [12-14]. The creation of the VR instruments has been previously documented [13-16] and has been shown to be valid for the VA population [13, 17-27] as well as other general I US populations [28-35]. The English-language VR instruments have become an integral part of registries [36] and studies of National U.S. health programs $[18,37-38]$ including the evaluation of the Medicare Advantage Program by the Centers for Medicare and Medicaid Services (CMS). Advantages of the VR instruments include their validity in older and sicker populations, their availability (all instruments are in the public domain) and their strong psychometric properties across different and wideranging socio-demographic and clinical groups.

In this study, we translated and culturally adapted the VR-36 into the German language (Germany) and validated the VR-36 and VR-12 in a population of German patients 
undergoing inpatient rehabilitation. The German VR-36 and VR-12 were comprehensively validated and compared to the SF-36 and SF-12 in inpatient populations of orthopedic and psychosomatic rehabilitation patients (the two largest clinical indications of German inpatient rehabilitation patients).

The SF-36 and the SF-12 are considered gold standards of self-assessed generic health instruments and they have been extensively distributed and used across a wide range of

countries, populations and purposes. They are recommended for measuring patient outcomes in the medical rehabilitation setting in Germany [39-42]. Since the field of medical rehabilitation has been one of the most common applications of the SF-36 in the Germanspeaking countries, it was important to compare the measurement properties of the VR instruments to the SF-instruments in this setting.

\section{METHODS}

The study was conducted in two phases: phase A) translating and culturally adapting the original English VR-36 into the German language (Germany); and phase B) validating the VR36 and its short version, the VR-12, in a randomized prospective study of inpatient rehabilitation patients with orthopedic and psychosomatic conditions.

\section{Phase A) Translation and cultural adaptation of the German VR}

The translation methodology followed a rigorous iterative forward-backward format to maintain the conceptual, functional, linguistic and cultural equivalence between the original (English) and the adapted (German) questionnaire. The translation procedure is summarized in Figure 1. First, a German translation of the VR-36 was produced from the English original 
version by an experienced translator (DB). Because the VR-36 is analogous to the SF-36, the German translation of the VR-36 items was (where ever possible) compared to items of the official German SF-36 (Version 1 [8-10] and Version 2 [43]). A first reconciled German VR-36 was produced after the forward translator (DB), the translation coordinator (TK, who was also the project manager) and the assistant to the translation coordinator (IB) discussed agreements and disagreements between the forward translation, SF-36 Version 1 and SF-36 Version 2 during a conference call. This first reconciled version of the questionnaire was then translated back into the source language (English) by an experienced translator (SF) who is a native speaker of English and fluent in German. The backward translation was compared to the original English VR-36 by the translation coordinator (TK) and the translation assistant (IB). Any discrepancies between the back translation and the English VR-36 were addressed with the back translator to determine the origins of discrepancies in the first reconciled German VR-36. After this stage, a second reconciled version of the German VR-36 was produced. This instrument was field tested with 26 general practice and rehabilitation patients with no cognitive or psychiatric impairments. Patients gave feedback about how easy it was to complete the instrument; whether items and response categories were clearly understood; and how easy it was to select the appropriate response category. After the field test, the final version of the German VR-36 was produced. The German VR-36 contains the subset of items for the VR-12.

\section{Phase B) Validation Study}

\section{Patient recruitment}


Patient recruitment took place in five rehabilitation clinics between October 2015 and November 2017. Eight hundred rehabilitation patients undergoing a three- or six-week inpatient rehabilitation due to an orthopedic $(n=400)$ or a psychosomatic $(n=400)$ indication who did not have cognitive or linguistic impairments provided written informed consent and were consecutively included in the study. Because the SF-36, the VR-36, the SF-12 and the VR12 questionnaires are very similar, participants were randomly assigned to one of four groups to complete only one of these instruments (Figure 2). By randomizing the patients, an indirect comparison between the long- and the short-forms of the VR and the SF could be made. Patients completed questionnaires at the beginning ( $\mathrm{t} 1$ ) and at the end $(\mathrm{t} 2)$ of rehabilitation. The study was approved by the ethics committee of the University Medicine Greifswald, Germany, and was conducted according to the Declaration of Helsinki.

$$
\text { *Please insert Figure } 2 \text { "Survey study design" about here* }
$$

\section{Measures}

In addition to the VR and SF instruments, the patient questionnaires contained several other self-report measures. These measures were chosen to correspond to the eight scales and the summary scores of the VR instruments.

The EQ-5 Dimensions 5-Level (EQ-5D-5L) is an internationally widely used preference-based measure of self-assessed health [44-46]. The questionnaire measures impairments in five dimensions of health using five items, each with five levels of impairments, and a thermometer-like visual analogue scale (EQ-VAS). The values of the five items can be 
converted into a preference-based single utility index. In the present study, index values were calculated using the German tariff [47].

The Centers for Disease Control and Prevention (CDC) "Healthy Days" is a generic healthrelated quality-of-life questionnaire (HRQOL) containing four items measuring self-rated health and the number of disability days (out of the last 30) due to physical, mental health or limitations in activities [48-49]. The instrument is valid and reliable [48].

The Hannover Functional Abilities Questionnaire (HFAQ), a 12-item functional questionnaire, is a generic measure of (physical) functional ability of daily activities [50-52]. Each item has three levels of function and the 12 items can be combined to produce an additive summary score.

The Depression, Anxiety and Stress Scale (DASS) is an extensively validated measure of mental health [53-54]. In this study, the short form (21-item, DASS21) instrument was used.

The Graded Chronic Pain Scale (GCPS) is an internationally established instrument developed by van Korff et al. [55-56]. The GCPS measures self-rated pain intensity and pain disability using a 0 to 10 numeric rating scale plus one item regarding number of disability days (in the past three months) due to pain using seven items. Summation of GCPS items produce scores describing pain intensity and pain disability.

The Index for the Assessment of Health Impairments, IMET [57-58], measures participation as defined by the WHO International Classification of Functioning, Disability and Health, ICF. The 9-item questionnaire was applied and tested in several samples from rehabilitation patients of different clinical indications. It is suitable as a screening method to assess the risk 
of a failure in the professional reintegration of rehabilitation patients. The instrument is demonstrated to be an economic, highly practicable, valid and reliable operationalization of "activities and participation" according to the concept of the ICF. Norm values for the IMET were assessed in a random sample of Lübeck inhabitants comprising subjects between 19 and 79 years of age, and enable classification of limitations in participation for people undergoing rehabilitation or suffering from chronic diseases.

The vitality subscale of the Indicators of the REhabilitation Status (IRES-VE) was included to examine the construct validity of the VR items on vitality [59]. In Germany, the IRES is recommended (in addition to the SF-36) for rehabilitation research and practice [42].

\section{Statistical analysis}

The VR-36 and the VR-12 were analyzed regarding the completeness of data on the scale-level, distributional properties, construct validity, known-groups validity, and responsiveness to change. This was done on the summary scores of the VR-36 and the VR-12 (physical component score $\left(\mathrm{PCS}_{\mathrm{VR}}\right)$ and mental component score $\left.\left(\mathrm{MCS}_{\mathrm{VR}}\right)\right)$ as well as the eight $\mathrm{VR}-36$ scales: (physical functioning (PFVR-36), role functioning/physical (RPVR-36), role functioning/emotional ( $\left.\mathrm{REVR}_{\mathrm{VR}-36}\right)$, vitality $\left(\mathrm{VT}_{\mathrm{VR}-36}\right)$, mental health ( $\left.\mathrm{MH}_{\mathrm{VR}-36}\right)$, social functioning $\left(S_{V R-36}\right)$, pain (BPVR-36), and general health $\left.\left(G_{V R-36}\right)\right)$. Summary scores and scales were scored according to the VR-36 and VR-12 algorithms, using a t-score transformation with a mean of 50 and a standard deviation of 10 and normed to a general sample of the US population for the summary scales (PCS and MCS) [23, 60-62]. Because the SF-36 and the SF-12 instruments are well validated across a range of populations, they were used as the comparator to the VR instruments for all analyses. 
145 Completeness of data is an indicator of data quality and acceptance of the questionnaire by 146 respondents. The percentage of non-missing responses was calculated for the eight VR-36 147 scales, stratified by respondent characteristics (e.g. clinical indication, age, sex, education).

Distributional properties (such as means, standard deviations and range) for the VR instruments were analyzed on the scale and summary score levels. To compare the distributional properties of the PCS and MCS for both the VR-12 and SF-12 as well as the VR36 and the SF-36, classical statistical indices of distribution such as mean, standard deviation, minimum, maximum, skewness (to assess and compare the type and strength of symmetry) and kurtosis (as a measure of the steepness / flatness of the frequency distribution) were assessed. Kolmogorow-Smirnov-test was used to compare the distributions of the two summary scores of the VR and the SF - i.e. PCS $\mathrm{VR}_{\mathrm{R}}$ and PCS SF as well as MCS $\mathrm{VR}_{\mathrm{R}}$ and $\mathrm{MCS}_{\mathrm{SF}}$. Kernel density plots using the Epanechnikov function were used to visually examine distribution of summary scores and scales.

Construct validity refers to the degree of accuracy with which a measurement instrument captures the construct it claims to measure. To examine construct validity, Pearson correlation coefficients $\left(r_{p}\right)$ between VR summary scores (PCS $S_{V R}$ and $M C S_{V R}$ ) and other self-completed health measures were assessed. We compared these to the correlations between the PCS $\mathrm{SF}$ and $\mathrm{MCS}_{\mathrm{SF}}$ with other self-completed health measures. Correlation coefficients were compared using significance tests for correlations for independent samples [63]. The correlations between PCSVR and other self-reported physical health measures (e.g. HFAQ, CDC 
than with self-report measures of mental health (divergent validity). Similarly, MCSVR is expected to be more strongly correlated with self-reported mental health measures (e.g. DASS-Anxiety, DASS-Stress, DASS-Depression, CDC Mental unhealthy days) than with physical measures. Both PCS and MCS are expected to be similarly correlated with generic self-report measures (e.g. EQ-VAS, IMET) and GCPS-Pain.

Known-groups validity is a criteria-based technique to investigate the ability of a measure to discriminate between groups known to differ in the construct of interest. For this study, known-groups were defined by clinical indication (psychosomatic, orthopedic), treatment program ("curative therapy" typically for chronically ill patients, "medical follow-up treatment" generally after joint replacement, only for orthopedic patients) age ( $<45$ years, 4565 years, $>65$ years), duration of rehabilitation (median), sick days in the past 12 month, selfrated health ("excellent/very good/good" vs. "fair/poor"). We examined if mean PCSVR and mean $\mathrm{MCS}_{\mathrm{VR}}$ scores were significantly different between those pre-defined groups using ttests for two groups or ANOVA for more than two groups.

Responsiveness refers to a self-assessed health instrument's ability to capture changes in health over time [64]. The raw difference of SF and VR summary scores from t1 to t2 were divided by the pooled standard deviation of change to produce standardized response means (SRM), or divided by baseline standard deviation to produce standardized effect size (SES). As we assess patients at the start and end of intensive therapy, we restricted this analysis to respondents who reported stable or improved health from t 1 to $t 2$ on a single self-rated health question ( $n=133$ ) to assess responsiveness to health improvements. We further checked 
improvement of scores (from baseline (t1) to first follow-up (t2) three to six weeks later) for all PCS- and MCS-scores of all four instruments using paired t-tests.

Data were analyzed using IBM SPSS Statistics 24 and STATA SE 13. Wherever applicable, analyses were stratified by patient clinical indication (orthopedic or psychosomatic rehabilitation).

\section{RESULTS}

\section{A) Translation and cultural adaptation of the German VR}

The field test yielded that most of the questions of the VR-36 are clear and simple to rehabilitation patients ( $n=15,4$ male, 11 female, 30 to 80 years (mean 55.3 years)) and patients from general practice ( $n=11,25$ to 77 years (mean 57.4 years)) of all ages.

Additional file 1 shows the key differences between the English VR and the German translation. The field test yielded that most of the questions (except for RE and RP instructions, response scales and questions) in the VR-36 are clear and simple to both patients from general practice and rehabilitation patients.

Nearly every third person had problems in answering items 12 to 15 (RP) due to double negatives introduced during the translation process (e.g. "[...] nicht so lange [...]" (part of the question) "nein, nie" (response option)). These double negatives were the result of combining the questions with their response choices. Therefore "yes" and "no" were omitted for these response categories to clarify the language. From a linguistic point of view, these revised response categories resemble the English SF-36 Version 2 and the German SF-36 (versions 1 and 2). Additionally, some cultural content were edited to reflect the German context (e.g. playing golf as an example in item PF02 would not be relevant as golf is a less popular activity 
in Germany). The German SF-36 was used as a guide in these decisions. The final German VR36 is conceptually identical to the English original.

\section{Phase B) Validation Study}

Data are available from $n=399$ orthopedic and $n=292$ psychosomatic rehabilitation patients.

Due to randomization, number and sample characteristics of participants were balanced across all four groups ( $n_{V R-36}=169, n_{S F-36}=174, n_{V R-12}=177, n_{S F-12}=171$ ). Study participants were on average 53 years old; $67.7 \%$ were women and $48.3 \%$ were fully employed. About every fourth participant (26.8\%) completed secondary education. Average duration of inpatient rehabilitation (for their primary diagnosis) was 22 days for orthopedic and 35 days for psychosomatic patients (overall mean=27.5 days). There were no systematic differences in the self-reported health status at baseline between the four study arms (CDC general health status $\left.p\left(\chi^{2}\right)>0.05\right)$

Socio-demographic and certain clinical characteristics were comparable across the four arms of the study, which allowed for indirect comparisons (Table 1). The most common primary M99: 48.9\%), affective disorders (ICD-10: F30.0-F39-0: 19.8\%) and neurotic, stress and somatoform disorders (ICD-10: F40.0-F49.0: 13.6\%).

\section{Completeness of data}

Missing values were acceptable ( $<5 \%)$ for the VR-36 and comparable to missing data 
240 increasing age and lower education.

TABLE 1 Sample characterization

\begin{tabular}{|c|c|c|c|c|}
\hline & VR-12 & SF-12 & VR-36 & SF-36 \\
\hline Number of cases $(n)$, of which were & 177 & 171 & 169 & 174 \\
\hline Orthopedics (\%) & 58.2 & 57.9 & 57.4 & 57.5 \\
\hline Psychosomatic (\%) & 41.8 & 42.1 & 42.6 & 42.5 \\
\hline Age (M $\pm S D)$ & $52.0 \pm 11.3$ & $53.2 \pm 11.3$ & $54.1 \pm 8.9$ & $52.0 \pm 10.7$ \\
\hline Sex (\% women) & 68.0 & 69.6 & 68.1 & 65.1 \\
\hline \multicolumn{5}{|l|}{ Marital status (\%) } \\
\hline Single & 13.4 & 13.9 & 8.6 & 17.3 \\
\hline Married/living with partner & 65.1 & 67.5 & 65.6 & 63.7 \\
\hline \multicolumn{5}{|l|}{ Highest school graduation (\%) } \\
\hline High school & 28.8 & 25.2 & 24.3 & 28.7 \\
\hline Secondary school (10 years) & 56.5 & 55.6 & 53.8 & 53.4 \\
\hline \multicolumn{5}{|l|}{ Employment status (\%) } \\
\hline Fully employed & 45.8 & 48.0 & 49.1 & 50.6 \\
\hline Pension application (\% „yes“) & 10.2 & 11.3 & 8.5 & 14.9 \\
\hline Duration of rehabilitation (mean days) & 26.8 & 28.2 & 27.4 & 27.7 \\
\hline Sick leave (days in the last year, $\mathrm{M} \pm \mathrm{SD}$ ) & $183 \pm 217$ & $164 \pm 209$ & $169 \pm 211$ & $155 \pm 200$ \\
\hline
\end{tabular}

36 Items Health Survey. All group comparisons were not significant ( $p>0.05)$.

TABLE 2 Percent complete items in each scale by instrument and patient subgroup

\begin{tabular}{|c|c|c|c|c|c|c|c|c|c|}
\hline & Instrument (n) & PF & $\mathbf{R P}$ & BP & GH & VT & SF & RE & MH \\
\hline \multirow[t]{2}{*}{ Total } & VR-36 ( $n=169)$ & 94.7 & 93.5 & 97.0 & 93.5 & 96.4 & 98.2 & 95.3 & 95.9 \\
\hline & SF-36 $(n=174)$ & 95.4 & 97.7 & 96.6 & 91.4 & 96.6 & 97.7 & 98.9 & 96.6 \\
\hline \multicolumn{10}{|l|}{$\begin{array}{l}\text { Clinical } \\
\text { indication }\end{array}$} \\
\hline \multirow[t]{2}{*}{ Orthopedic } & VR-36 ( $n=97)$ & 93.8 & 91.8 & 96.9 & 92.8 & 95.9 & 97.9 & 93.8 & 92.8 \\
\hline & SF-36 (n=100) & 94.0 & 98.0 & 97.0 & 90.0 & 95.0 & 97.0 & 99.0 & 95.0 \\
\hline \multirow[t]{2}{*}{ Psychosomatic } & VR-36 $(n=72)$ & 95.8 & 95.8 & 97.2 & 94.4 & 97.2 & 98.6 & 97.2 & 100.0 \\
\hline & SF-36 $(n=74)$ & 97.3 & 97.3 & 95.9 & 93.2 & 98.6 & 98.6 & 98.6 & 98.6 \\
\hline \multicolumn{10}{|l|}{ Sex } \\
\hline \multirow[t]{2}{*}{ Female } & VR-36 $(n=111)$ & 91.9 & 94.6 & 96.4 & 94.6 & 96.4 & 98.2 & 94.6 & 96.4 \\
\hline & SF-36 $(n=112)$ & 94.6 & 97.3 & 95.5 & 87.5 & 95.5 & 97.3 & 98.2 & 95.5 \\
\hline Male & VR-36 ( $n=52)$ & 100.0 & 90.4 & 98.1 & 92.3 & 96.2 & 98.1 & 96.2 & 94.2 \\
\hline
\end{tabular}




\begin{tabular}{|c|c|c|c|c|c|c|c|c|c|}
\hline \multirow{2}{*}{\multicolumn{10}{|c|}{$\begin{array}{l}\text { SF-36 }(n=60) \\
\text { Age (median split) }\end{array}$}} \\
\hline & & & & & & & & & \\
\hline$\leq 54$ years & VR-36 (n=77) & 96.1 & 94.8 & 97.4 & 96.1 & 97.4 & 100.0 & 97.4 & 96.1 \\
\hline \multirow{2}{*}{$\begin{array}{l}\leq 53 \text { years } \\
>54 \text { years }\end{array}$} & SF-36 $(n=87)$ & 97.7 & 97.7 & 97.7 & 93.1 & 98.9 & 98.9 & 98.9 & 98.9 \\
\hline & VR-36 (n=86) & 93.0 & 91.9 & 96.5 & 91.9 & 95.3 & 96.5 & 93.0 & 95.3 \\
\hline \multirow{2}{*}{\multicolumn{10}{|c|}{$\begin{array}{l}>53 \text { years } \\
\text { Education }\end{array}$}} \\
\hline & & & & & & & & & \\
\hline \multirow[t]{2}{*}{$\leq 10$ years } & VR-36 $(n=115)$ & 93.0 & 91.3 & 95.7 & 92.2 & 95.7 & 98.3 & 93.0 & 93.9 \\
\hline & SF-36 $(n=117)$ & 94.9 & 98.3 & 95.7 & 91.5 & 95.7 & 97.4 & 99.1 & 95.7 \\
\hline \multirow[t]{2}{*}{$>10$ years } & VR-36 (n=46) & 97.8 & 97.8 & 100.0 & 95.7 & 97.8 & 97.8 & 100.0 & 100.0 \\
\hline & SF-36 $(n=55)$ & 96.4 & 96.4 & 98.2 & 90.9 & 98.2 & 98.2 & 98.2 & 98.2 \\
\hline
\end{tabular}

249

250

251

252

253

254

255

256

257

258

259

260

261

262

263

264

265

PF Physical Functioning, RP Role Physical, BP Bodily Pain, GH General Health, VT Vitality, SF

Social Functioning, RE Role Emotion, MH Mental Health, $\mathrm{n}$ sample size

\section{Distributional properties}

Table 3 gives the distributional properties of the PCS and MCS for the VR and SF short and long form versions. Means, standard deviations and ranges for PCS were very similar between SF-36 and VR-36, SF-12 and VR-12. For MCS, mean differences (e.g. mean VR-36: 36.2, mean SF-36: 39.0), skewness, kurtosis and boundary values of the distribution were larger between the SF-36 and VR-36 than between the SF-12 and VR-12.

For the long and the short form versions of the VR and the SF, the PCS has normal distributions ( $p=0.057$ to 0.097 ) while the MCS does not $(p<0.05$, Table 3 ). The findings do not substantively change when stratified by study arm and clinical indication (results not shown).

TABLE 3 Distribution properties of PCS and MCS by instrument and version

\begin{tabular}{|l|l|l|l|l|l|l|}
\hline Instrument & $\mathbf{n}$ & $\mathbf{M} \pm \mathbf{~ S D}$ & Min-Max & Kurtosis & Excess & K-S-Test \\
\hline PCS $_{\text {VR-36 }}$ & 155 & $38.50 \pm 10.15$ & $11.74-67.81$ & 0.151 & -0.226 & $\mathbf{0 . 2 0 0}$ \\
\hline MCS $_{\text {VR-36 }}$ & 155 & $36.18 \pm 14.21$ & $12.92-66.56$ & 0.437 & -0.817 & 0.049 \\
\hline PCS $_{\text {VR-12 }}$ & 173 & $36.30 \pm 11.55$ & $12.7-59.3$ & 0.141 & -0.969 & $\mathbf{0 . 0 5 7}$ \\
\hline
\end{tabular}




\begin{tabular}{|l|l|l|l|l|l|l|}
\hline MCS $_{\text {VR-12 }}$ & 173 & $37.23 \pm 13.82$ & $8.36-70.16$ & 0.389 & -0.527 & 0.001 \\
\hline PCS $_{\text {SF-12 }}$ & 150 & $36.95 \pm 10.95$ & $15.5-61.6$ & 0.27 & -0.724 & $\mathbf{0 . 0 6 0}$ \\
\hline MCS $_{\text {SF-12 }}$ & 150 & $39.04 \pm 12.33$ & $17.6-65.4$ & 0.268 & -1.001 & 0.002 \\
\hline PCS SF-36 & 168 & $37.50 \pm 11.67$ & $13.8-66.12$ & 0.289 & -0.465 & $\mathbf{0 . 0 9 7}$ \\
\hline MCS $_{\text {SF-36 }}$ & 168 & $39.03 \pm 15.62$ & $2.04-73.17$ & 0.055 & -0.989 & 0.005 \\
\hline
\end{tabular}

K-S-Test Kolmogorov-Smirnov-Test, M mean, SD standard deviation, $\mathrm{n}$ sample size

The VR-36 scales distribute toward slightly lower scores than the SF-36 on the MCS, but not

for the PCS. Kernel density plots show that the four instruments were more similar in PCS for

orthopedic and MCS for psychosomatic patients. The distributions were more similar

between the SF-12 and the SF-36 than between the SF and the VR instruments in PCS for

psychosomatic and MCS for orthopedic patients (Figure 3a). Differences were observed after

stratifying by clinical indication. For the scales of the instruments, kernel plots of the VR-36

and the SF-36 are comparable for PF and BP, RP and RE, while kernel plots of SFVR-36, VTVR-36 and $\mathrm{MH}_{\mathrm{VR}-36}$ are slightly more left skewed compared to the SF-36 (Figure 3b).

*Please insert Figure 3a "Kernel density estimation for PCS and MCS" about here*

*Please insert Figure 3b "Kernel plots of the scales of the VR-36 and SF-36" about here*

\section{Construct validity}

Table 4 presents the correlations between VR and SF component scores and other self-

reported measures. Moderate to high correlations were observed between convergent measures with similar correlations observed across the VR-12 and SF-12, and VR-36 and SF36. $R_{p}$ between PCS and HFAQ, CDC Physical unhealthy days, GCPS Level and GCPS Disability ranged from $r_{p}=0.50$ to $r_{p}=0.76 ; r_{p}$ between MCS and DASS-measures, CDC Mental unhealthy days and IRES-VT ranged from $r_{p}=0.5$ to $r_{p}=0.8$. 
Correlation coefficients with generic measures ranged from $r_{p}=0.08$ to $r_{p}=0.49$ for the VR-36

289

290

291

292

293

294

295

296

297

298

299

300

301

302

303

304

305

306

307

and from $r_{p}=0.012$ to $r_{p}=0.42$ for the SF-36. For the short versions, those correlations varied from $r_{p}=0.06$ to $r_{p}=0.62$ for the VR-12 and from $r_{p}=0.17$ to $r_{p}=0.51$ for the SF-12. Differences $(\Delta)$ of correlations between corresponding measures (PCS: HFAQ, CDC healthy days physical unhealthy days; MCS: DASS, IRES-VT, CDC mental unhealthy days) were below $r_{p}=0.090$ and with one exception (IRES-VT vs. MCS for the short versions) statistically not significant $(p>0.5)$.

The PCS $\mathrm{VR}_{\mathrm{R}}$ had moderate correlations $\left(r_{p}=0.33\right.$ to $\left.r_{p}=0.62\right)$ with generic measures and moderate to strong correlations $\left(r_{p}=-0.55\right.$ to $\left.r_{p}=0.76\right)$ with physical health measures. The $M C_{V R}$ had small to moderate correlation with generic health measures $\left(r_{p}=0.32\right.$ to $\left.r_{p}=0.49\right)$ and moderate to strong correlations with mental health measures $\left(r_{p}=-0.60\right.$ to $\left.r_{p}=0.78\right)$. At $r_{p}=-0.5\left(P C S_{S F-12}\right)$ and $r_{p}=-0.6\left(P C S_{V R-12}\right)$, the correlation between the short versions of the PCS and the GCPS Pain was greater than for the long versions (both PCS $\mathrm{PF}-36_{6}$ and PCSVR-36 $\mathrm{r}_{\mathrm{p}}=-$ 0.4). The MCS of all versions was almost uncorrelated with the GCPS Pain ( $r_{p}=-0.172$ to $\left.r_{p}=0.013\right)$.

*Please insert Table 4 about here*

TABLE 4 Construct validity: Comparison of Pearson correlation coefficients $\left(r_{p}\right)$ across SF-

12/VR-12 and SF-36/VR-36

\begin{tabular}{|c|c|c|c|c|c|c|c|}
\hline $\begin{array}{l}\text { Physical Component score } \\
\text { (PCS) }\end{array}$ & $\mathrm{PCS}_{\mathrm{SF}-12}$ & PCS $_{\mathrm{VR}-12}$ & $\Delta_{\text {SF-12-VR-12 }}$ & p-value & $\mathrm{PCS}_{\mathrm{SF}-36}$ & $\mathrm{PCS}_{\mathrm{VR}-36}$ & $\Delta_{\text {SF-36-VR-36 }}$ \\
\hline \multicolumn{8}{|l|}{ Generic } \\
\hline EQ-VAS & 0.480 & 0.327 & 0.153 & 0.052 & 0.348 & 0.328 & 0.020 \\
\hline IMET & -0.499 & -0.514 & 0.015 & 0.429 & -0.362 & -0.457 & 0.095 \\
\hline GCPS Pain & -0.514 & -0.620 & 0.106 & 0.082 & -0.420 & -0.412 & -0.008 \\
\hline \multicolumn{8}{|l|}{ Convergent } \\
\hline HFAQ & 0.670 & 0.759 & -0.089 & 0.052 & 0.746 & 0.660 & 0.086 \\
\hline CDC physical healthy days & -0.604 & -0.669 & 0.065 & 0.165 & -0.569 & -0.554 & -0.015 \\
\hline
\end{tabular}




\begin{tabular}{|lrrrrrrr|} 
GCPS Pain Intensity & -0.547 & -0.624 & 0.077 & 0.149 & -0.664 & -0.632 & -0.032 \\
GCPS Pain Disability & -0.581 & -0.615 & 0.034 & 0.319 & -0.661 & -0.586 & -0.075 \\
\hline Divergent & & & & & & & \\
DASS Anxiety & -0.156 & 0.003 & -0.159 & 0.085 & 0.143 & -0.094 & 0.237 \\
DASS Depression & 0.023 & 0.124 & -0.101 & 0.183 & 0.164 & -0.005 & 0.169 \\
DASS Stress & 0.063 & 0.109 & -0.046 & 0.340 & 0.297 & 0.104 & 0.193 \\
IRES -VT & 0.106 & -0.082 & 0.188 & 0.415 & -0.151 & -0.015 & -0.136 \\
CDC Mentally healthy days & 0.174 & 0.119 & 0.055 & 0.309 & 0.234 & 0.118 & 0.116 \\
\hline
\end{tabular}

\begin{tabular}{|c|c|c|c|c|c|c|c|}
\hline $\begin{array}{l}\text { Mental Component score } \\
\text { (MCS) }\end{array}$ & $\mathrm{MCS}_{\mathrm{SF}-12}$ & $\mathrm{MCS}_{\mathrm{VR}-12}$ & $\Delta_{\mathrm{SF}-12-\mathrm{VR}-12}$ & p-value & $\mathrm{MCS}_{\mathrm{SF}-36}$ & $\mathrm{MCS}_{\mathrm{VR}-36}$ & $\Delta_{\text {SF-36-VR-36 }}$ \\
\hline \multicolumn{8}{|l|}{ Generic } \\
\hline$E Q-V A S$ & 0.311 & 0.321 & -0.010 & 0.461 & 0.282 & 0.451 & -0.169 \\
\hline IMET & -0.420 & -0.426 & 0.006 & 0.474 & -0.392 & -0.490 & 0.098 \\
\hline GCPS Pain & -0.172 & -0.062 & -0.110 & 0.162 & 0.013 & -0.080 & 0.093 \\
\hline \multicolumn{8}{|l|}{ Divergent } \\
\hline HFAQ & 0.054 & -0.137 & 0.191 & 0.045 & -0.141 & 0.036 & -0.177 \\
\hline CDC Physical healthy days & -0.046 & 0.064 & -0.110 & 0.166 & 0.020 & -0.146 & 0.166 \\
\hline GCPS Pain Intensity & -0.154 & -0.013 & -0.141 & 0.069 & 0.091 & -0.100 & 0.191 \\
\hline GCPS Pain Disability & 0.072 & -0.031 & 0.103 & 0.182 & 0.022 & -0.159 & 0.181 \\
\hline \multicolumn{8}{|l|}{ convergent } \\
\hline DASS Depression & -0.772 & -0.729 & -0.043 & 0.192 & -0.788 & -0.734 & -0.054 \\
\hline DASS Anxiety & -0.524 & -0.596 & 0.072 & 0.177 & -0.603 & -0.609 & 0.006 \\
\hline DASS Stress & -0.673 & -0.702 & 0.029 & 0.314 & -0.796 & -0.729 & -0.067 \\
\hline IRES-VT & 0.701 & 0.784 & -0.083 & 0.050 & 0.806 & 0.763 & 0.043 \\
\hline CDC Mentally healthy days & -0.744 & -0.746 & 0.002 & 0.484 & -0.684 & -0.704 & 0.020 \\
\hline
\end{tabular}

CDC healthy days, EQ-5D-5L EuroQol-5 Dimensions, HFAQ Hannover Functional Ability

Questionnaire, IMET Index of the Assessment of Health Impairments, IRES-VT Subscale

Vitality of the "Indicators of Rehabilitation Status", GCPS Graded Chronic Pain Scale, SF-12

311 Short-Form 12 Items Health Survey, SF-36 Short Form 36 Items Health Survey, VR-12

312 Veterans Rand 12 Items Health Survey, VR-36 Veterans Rand 36 Items Health Survey; p-value

313 for the comparison of two correlation coefficients from independent samples [63].

\section{Known-groups validity}

316 Table 5a illustrates the PCSVR-36 and $\mathrm{MCS}_{V R-36}$ scores in sub-samples of known groups. Lower

317 mean PCS ${ }_{V R-36}$ was found for orthopedic patients while lower mean MCS $_{V R-36}$ was found for

318 psychosomatic patients. In line with our hypothesis, higher mean PCSVR-36 and MCSVR-36

319 scores were found in younger patients with fewer sick days in the last year and a shorter 
321 mental health compared to psychosomatic patients and the other way around for mental

322 health, which is reflected by higher mean MCSVR-36 Scores in orthopedic and higher mean

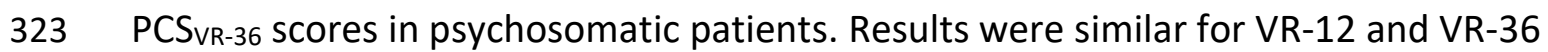

324 suggesting that both instruments perform similarly with respect to known-groups validity

325 (Table 5b).

*Please insert Table $\mathbf{5 a}$ and $\mathbf{5 b}$ about here*

TABLE 5a Known groups validity for the PCSVR-36 and the MCSVR-36

\begin{tabular}{|c|c|c|c|c|}
\hline \multirow{2}{*}{ Subgroups } & \multicolumn{2}{|c|}{ PCSVR-36 } & \multicolumn{2}{|c|}{ MCSVR-36 } \\
\hline & mean \pm SD & p-value & mean \pm SD & $p$-value \\
\hline \multicolumn{5}{|l|}{ Clinical Indication } \\
\hline Psychosomatic patients $(n=68)$ & $44.08 \pm 8.78$ & $<0.001$ & $28.86 \pm 11.01$ & $<0.001$ \\
\hline Orthopedic patients $(n=87)$ & $34.18 \pm 8.99$ & & $41.90 \pm 13.85$ & \\
\hline \multicolumn{5}{|l|}{ Type of therapy ${ }^{1}$} \\
\hline Medical follow-up-treatment $(n=30)$ & $29.57 \pm 8.90$ & $<0.001$ & $44.11 \pm 13.92$ & 0.149 \\
\hline Curative treatment $(n=54)$ & $36.70 \pm 8.13$ & & $39.63 \pm 13.26$ & \\
\hline \multicolumn{5}{|l|}{ Age } \\
\hline$<45$ years $(n=25)$ & $41.34 \pm 8.38$ & & $31.77 \pm 13.60$ & \\
\hline $45-65$ years $(n=114)$ & $38.34 \pm 10.67$ & 0.181 & $37.53 \pm 14.38$ & 0.133 \\
\hline$>65$ years $(n=16)$ & $35.45 \pm 7.96$ & & $33.45 \pm 12.91$ & \\
\hline \multicolumn{5}{|l|}{ Duration of rehabilitation } \\
\hline$\leq 27$ days $(n=71)$ & $35.21 \pm 9.15$ & $<0.001$ & $40.65 \pm 13.52$ & $<0.001$ \\
\hline$>27$ days $(n=66)$ & $42.41 \pm 10.28$ & & $32.52 \pm 13.10$ & \\
\hline \multicolumn{5}{|l|}{ Sick days ${ }^{2}$} \\
\hline$\leq 100$ days $(n=76)$ & $40.30 \pm 10.62$ & 0.081 & $38.14 \pm 14.10$ & 0.281 \\
\hline$>100$ days $(n=66)$ & $37.29 \pm 9.66$ & & $35.59 \pm 13.95$ & \\
\hline \multicolumn{5}{|l|}{ SRH $^{3}$} \\
\hline Excellent/very good/good $(n=60)$ & $42.68 \pm 10.97$ & $<0.01$ & $43.40 \pm 13.33$ & $<0.001$ \\
\hline Fair/poor $(n=92)$ & $35.65 \pm 8.66$ & & $31.81 \pm 13.01$ & \\
\hline
\end{tabular}

${ }^{1}$ Orthopedic patients only. ${ }^{2}$ Days of sick leave in the last 12 month. ${ }^{3}$ SRH Self-rated health.

Patients reporting "excellent", "very good" or "good" health and those reporting "poor" or

"fair" health were aggregated. SD standard deviation.

TABLE 5b Known groups validity for the $\mathrm{PCS}_{\mathrm{VR}-12}$ and $\mathrm{MCS}_{\mathrm{VR}-12}$ 


\begin{tabular}{|c|c|c|c|c|}
\hline & mean \pm SD & $p$-value & mean \pm SD & $p$-value \\
\hline $\begin{array}{l}\text { Clinical Indication } \\
\text { Orthopedic patients }(n=100) \\
\text { Psychosomatic patients }(n=73)\end{array}$ & $\begin{array}{r}31.20 \pm 9.49 \\
43.13 \pm 10.55 \\
\end{array}$ & $<0.001$ & $\begin{array}{l}42.21 \pm 13.73 \\
30.41 \pm 10.74\end{array}$ & $<0.001$ \\
\hline $\begin{array}{l}\text { Type of therapy }{ }^{1} \\
\text { Medical follow-up treatment }(n=37) \\
\text { Curative therapy }(n=67)\end{array}$ & $\begin{array}{l}28.37 \pm 9.67 \\
32.88 \pm 9.20 \\
\end{array}$ & 0.023 & $\begin{array}{l}44.56 \pm 15.34 \\
40.58 \pm 12.42\end{array}$ & 0.187 \\
\hline $\begin{array}{l}\text { Age } \\
<45 \text { years }(n=42) \\
45-65 \text { years }(n=111) \\
>65 \text { years }(n=20)\end{array}$ & $\begin{array}{l}37.15 \pm 11.77 \\
36.86 \pm 11.37 \\
30.78 \pm 11.13 \\
\end{array}$ & 0.079 & $\begin{array}{l}35.84 \pm 14.14 \\
36.02 \pm 12.94 \\
46.87 \pm 14.77 \\
\end{array}$ & 0.004 \\
\hline $\begin{array}{l}\text { Duration of rehabilitation } \\
\leq 27 \text { days }(n=85) \\
>27 \text { days }(n=71)\end{array}$ & $\begin{array}{r}31.69 \pm 10.74 \\
41.77 \pm 9.91 \\
\end{array}$ & $<0.001$ & $\begin{array}{l}42.45 \pm 13.64 \\
31.89 \pm 11.64 \\
\end{array}$ & $<0.001$ \\
\hline $\begin{array}{l}\text { Sick days }^{2} \\
\leq 100 \text { days }(n=82) \\
>100 \text { days }(n=82)\end{array}$ & $\begin{array}{l}38.56 \pm 10.71 \\
34.41 \pm 12.04\end{array}$ & 0.021 & $\begin{array}{l}37.58 \pm 13.66 \\
36.65 \pm 13.96\end{array}$ & 0.667 \\
\hline $\begin{array}{l}\text { SRH }^{3} \\
\text { Excellent/very good/good ( } n=67) \\
\text { Fair/poor }(n=104)\end{array}$ & $\begin{array}{l}41.56 \pm 11.49 \\
32.38 \pm 10.19 \\
\end{array}$ & $<0.001$ & $\begin{array}{l}43.42 \pm 13.81 \\
33.50 \pm 12.37\end{array}$ & $<0.001$ \\
\hline
\end{tabular}

${ }^{1}$ Orthopedic patients only. ${ }^{2}$ Days of sick leave in the last 12 month. ${ }^{3}$ SRH Self-rated health.

Patients reporting "excellent", "very good" or "good" health and those reporting "fair" or "poor" health were aggregated. SD standard deviation.

\section{Responsiveness}

Responsiveness to change analysis included the $n=50$ to $n=88$ cases with no deterioration in

SRH from baseline (t1) to follow-up (t2), stratified as necessary by study arm (Table 6). For

PCS, SES varied from 0.102 (VR-36 Psychosomatic) to 0.398 (SF-12 Orthopedic) and SRM

varied from 0.127 (VR-36 Psychosomatic) to 0.695 (VR-12 Orthopedic) with better

responsiveness across all instruments for orthopedic patients. Effect sizes of the short

versions (VR-12, SF-12) were larger than those of the long versions (VR-36, SF-36). In

psychosomatic patients, responsiveness to change of MCS was at least twice as large as

responsiveness of PCS, while in orthopedic patients there were less obvious differences in

psychosomatic patients was smaller than the other instruments. Score improvements for all 
TABLE 6 Standardized Response Means (SRM) and Standardized Effect Sizes (SES) by

instrument and clinical indication

\begin{tabular}{|l|c|c|c|c|c|c|c|c|c|c|}
\hline & \multicolumn{5}{|c|}{ Orthopedics } & \multicolumn{4}{c|}{ Psychosomatics } \\
\hline & & \multicolumn{2}{|c|}{ SES } & \multicolumn{2}{c|}{ SRM } & & \multicolumn{2}{c|}{ SES } & \multicolumn{2}{c|}{ SRM } \\
\hline Version & $\mathbf{n}_{\mathbf{i} / \mathbf{s}}\left(\mathbf{n}_{\mathbf{c}}\right)$ & PCS & MCS & PCS & MCS & $\mathbf{n}_{\mathbf{i} / \mathbf{s}}\left(\mathbf{n}_{\mathbf{c}}\right)$ & PCS & MCS & PCS & MCS \\
\hline VR-36 & $78(82)$ & 0.235 & 0.298 & 0.328 & 0.452 & $56(61)$ & 0.102 & 0.522 & 0.127 & 0.527 \\
\hline SF-36 & $83(88)$ & 0.317 & 0.165 & 0.460 & 0.241 & $59(60)$ & 0.250 & 0.818 & 0.331 & 0.820 \\
\hline VR-12 & $88(93)$ & 0.381 & 0.357 & 0.545 & 0.586 & $50(57)$ & 0.218 & 1.027 & 0.317 & 0.876 \\
\hline SF-12 & $63(69)$ & 0.398 & 0.482 & 0.695 & 0.586 & $50(54)$ & 0.277 & 0.840 & 0.357 & 1.060 \\
\hline
\end{tabular}

SES standardized effect size, SRM standardized response mean, $\mathrm{n}_{\mathrm{i} / \mathrm{s}}$ number of patients

reporting improved or stable health defined by GHP1 (self-rated health, item 1 of the SF-36),

$\mathrm{n}_{\mathrm{c}} \mathrm{n}$ complete: number of all cases, PCS physical summary score, MCS mental summary score

\section{DISCUSSION}

This research project 1) translated and culturally adapted the English VR-36 to the German language (Germany) and 2) validated the adapted VR-36 and VR-12 in German orthopedic and psychosomatic inpatient rehabilitation patients. This article provides details of the translation and cultural adaptation process of the German VR and the main findings of the validation study.

The German translation of the VR was prepared according to "state of the art" criteria for cultural adaptation of self-assessed health questionnaires using forward and backward translations. The study produced a self-report questionnaire that is conceptually and semantically equivalent to the English language VR-36. The only difficulty during translation was the role physical (RP) and role emotional (RE) items which produced double negatives 
when the question stems and responses were taken together. This was resolved by a slight change in response category wording.

The German VR-36 is the third cultural adaptation and translation of the VR after the Spanish and the Chinese version. Three more language versions (Japanese, Russian, Polish) are being planned. ${ }^{1}$

The validation phase of this study found the VR instruments to be acceptable, valid and moderately to strongly responsive to improvements in health. We indirectly compared the German VR-36 and VR-12 to the well-established SF-36 and SF-12, and found the instruments to be comparable in their distribution properties, validity, and responsiveness. Data quality indicators, such as the extent of item non-response, show the VR to be acceptable instruments in a German rehabilitation population, and were similar compared to the SF instruments. PCS score distributions were similar for VR and SF instruments. However, the MCS $\mathrm{VR}_{\mathrm{V}}$ was distributed more in the lower range of the scale than the MCS $\mathrm{SF}$. The VR scales and summary scores were moderately to strongly correlated with expected external measures such as self-reported pain, physical functioning, mental functioning and disability.

Both the long and the short form of the VR could distinguish between patient type (orthopedic and psychosomatic), duration of rehabilitation and self-rated health while the PCSVR-12 could also distinguish between type of therapy and whether the patient had over 100 sick days in the year. The short version (VR-12) was similarly responsive as the VR-36 and SF-36. Thus, the VR was established as a valid and responsive measure of quality of life in orthopedic and psychosomatic samples of German inpatient rehabilitation patients.

\footnotetext{
${ }^{1}$ To request free access to the instruments, information on terms of use, name and institution can be found at Boston University's website [65]. The scoring algorithms for SAS, R, SPSS and Stata are available from Prof. L.E. Kazis.
} 
The number of studies using one of the instruments of the VR family is increasing every year with well over 400 publications [65]. The developers of the VR family provided the original psychometric evidence for the VR-36 and VR-12 [13;15-16;23].

Item level missing values were low and comparable to other studies suggesting high acceptability. While in this study $1.8 \%$ to $6.5 \%$ were missing per question for the baseline VR-36, Kronzer et al. [67] reported missing values in adult patients undergoing elective surgery on the baseline VR-12 from $1.5 \%$ to $3.7 \%$ per question and from $3.3 \%$ to $8.9 \%$ on the follow-up VR-12 (median 56 days).

Descriptive statistics indicated acceptable distributional characteristics. Summary scale means and SD of the PCSVR-36 are comparable with the results of the Veterans Health Study, in which the VR-36 was administered to nearly 2,500 veterans receiving ambulatory care

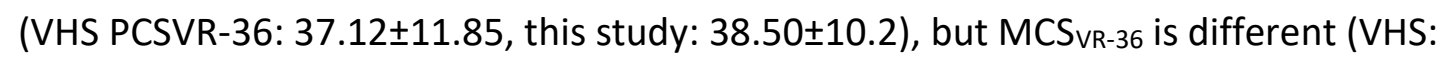

47.81 \pm 12.23 , this study: $36.2 \pm 14.2$ ) [17]. The differences in MCS may be a function of the populations sampled; while the means were different the SD are quite similar.

The validity results are comparable with other studies investigating physically impaired patients: a study with patients undergoing knee arthroplasty [31] found a moderate correlation between the PCSVR-12 and a disease-specific measure (KOOS-pain score: 0.57 ). Few studies investigated the factor structure of the VR-36 and found its structure to be comparable to the SF-36 [60].

Oak et al [31] found the PCSVR-12 to capture statistically significant improvements in the score in $\mathrm{n}=45$ pre- and postoperatively tracked patients who underwent knee arthroplasty. They 
found no statistical differences in internal or external responsiveness to change among the EQ-5D, VR-12 and PROMIS 10 physical instruments with SRMs of the PCSVR-12 of 0.681 and for the MCSVR-12 of 0.103 (SRM EQ-5D: 0.704, PROMIS 10 physical 0.721, PROMIS 10 mental 0.083). SRM of VR-12 scores at baseline and at the end of therapy (0.549) can be calculated from results of Levy et al.'s (2015) study of physical therapy received through telerehabilitation [68]. This is extremely similar to what we found for the VR-12 in orthopedic patients. Bedigrew et al.'s [69] study of an orthotic and rehabilitation program found statistically significant improvements only in the PCS and not in the MCS. For orthopedic patients, we found PCS to be less sensitive to changes in both SF and VR than the MCS, with the VR-12 similar or more sensitive to improvements than the SF instruments. However, the VR 36 was found to be slightly less sensitive to improvements than the SF-36 for psychosomatic patients.

Although the VR-36 and VR-12 are based on version 1 of the SF-36 and SF-12, the VR instruments use the five-level response format of the role functioning and role emotional scales whereas the SF version 1 instruments use the two-level format. The SF version 2 uses five-level response scales for those scales, but has slightly different wording and is in general a different instrument than version 1 . This difference is likely the source of differences in distribution and responsiveness in our comparison of the VR to SF version 1 instruments. The floor was raised and ceiling lowered with the 5-point set of response choices for the role physical and role emotional scales compared with the dichotomized choices for the SF version 1 instruments [16]. Previous findings suggest that this could also be a possible explanation for the differences in responsiveness [16]. Gornet et al. [35] investigated the conversion of the SF-36 to PCS $\mathrm{VR}-12$ and $\mathrm{MCS}_{\mathrm{VR}-12}$ in 1,968 patients who underwent lumbar 
$(n=1,559)$ and cervical $(n=409)$ surgery between 1998 and 2013. They found the SF-36 and converted VR-12 mean scores, the mean (pre to post) change scores for PCS and MCS, and

443 the minimum detectable change (MDC) to be extremely similar. However, as their study only

444 collected SF-36 data, they could not compare how a 2-level and 5-level response category in 445 the two scales might differ.

The primary limitation of this study is the indirect comparison of the instruments: the VR-36, VR-12, SF-36 and SF-12 were completed by different patients. The design choice was to minimize respondent burden and frustration as the four instruments are very similar. Although patients were randomized to the study arms, there could be underlying differences across the groups not captured by demographic or patient characteristics. Thus, it is possible that the detected distribution and responsiveness differences may in part be due to differences in the sample characteristics and perhaps unmeasured variables and not due to the instruments themselves.

Furthermore, the German VR was validated in an inpatient rehabilitation setting, and the results may not be generalizable to other populations nor to outpatient rehabilitation settings. Future research applying the German VR in other settings is necessary. The instruments were also administered only as a paper-and-pencil survey. As self-assessment questionnaires are increasingly being used in electronic formats, the comparison between the classical paper-pencil and other new computer platform applications should be studied.

\section{CONCLUSIONS}

463 The VR is a credible measure in the public domain that can be applied in the German rehabilitation context. The VR measure may be appropriate for use in clinical research and 
clinical practice, but further research is needed to evaluate its usefulness in other populations in German. Due to the high demand for the German VR during the study period, it can be assumed that in the foreseeable future more data from different clinical settings and administrative modes will be available. The scoring algorithms also have been developed by the project working group for common statistical programs (e.g. SPSS, Stata, R) and is, as well as the questionnaires, freely available for use to the research community.

\section{REFERENCES}

[1] Scoggins JF, Patrick DL. The use of patient-reported outcomes instruments in registered clinical trials: Evidence from ClinicalTrials.gov. Contemporary Clinical Trials. 2009;30:289292.

[2] Calvert M, Kyte D, Duffy H, Gheorghe A, Mercieca-Bebber R, Ives J, Draper H, Brundage M, Blazeby J, King M. Patient-Reported Outcome (PRO) Assessment in Clinical Trials: A Systematic Review of Guidance for Trial Protocol Writers. PLoS One. 2014;9(10):e110216. [3] Hennessy CH, Moriarty DG, Zack MM, Scherr PA, Brackbill R. Measuring health-related quality of life for public health surveillance. Public Health Rep. 1994;109(5):665-672. [4] Spitzer RL, Kroenke K, Linzer M et al. Health-Related Quality of Life in Primary Care Patients With Mental Disorders. Results From the PRIME-MD 1000 Study. JAMA. 1995;274(19):1511-7.

[5] Bowling A, Windor J. Towards the Good Life: A Population Survey of Dimensions of Quality of Life. Journal of Happiness Studies. 2001;2(1):55-82.

[6] Zahran HS, Kobau R, Moriarty DG, Zack MM, Holt J, Donehoo R. Health-Related Quality of Life Surveillance - United States, 1993-2002. Morbidity and Mortality Weekly Report: Surveillance Summaries. 2005;54(4):1-35. 
[7] Saarni SI, Härkänen T, Sintonen H et al. The Impact of 29 Chronic Conditions on Healthrelated Quality of Life: A General Population Survey in Finland Using 15D and EQ-5D. Qual Life Res. 2006;15(8):1403-8.

[8] Ware JE, Sherbourne CD. The MOS 36-Item Short-Form Health Survey (SF-36). I.

Conceptual Framework and item Selection. Medical Care. 1992;30(6):473-483.

[9] McHorney CA, Ware JE, Raczek AE. The MOS 36-Item Short-Form Health Survey (SF-36):

II. Psychometric and Clinical Tests of Validity in Measuring Physical and Mental health Constructs. Medical Care. 1993;31(3):247-263.

[10] McHorney CA, Qare JE, Lu JF, Sherbourne CD. The MOS 36-Item Short-Form Health Survey (SF-36); III. Tests of Data Quality, Scaling Assumptions, and Reliability across Diverse Patient Groups. Medical Care. 1994;32(1):40-66.

[11] Boston University School of Public Health Site. About the VR-36, VR-12 and VR-6D.

https://www.bu.edu/sph/about/departments/health-law-policy-and-

management/research/vr-36-vr-12-and-vr-6d/about-the-vr-36-vr-12-and-vr-6d/ Accessed 17 Sept 2018.

[12] Wolinsky FD, Coe RM, Mosely RR, et al. Veterans and nonveterans use of health services: a comparative analysis. Med Care. 1985;23:1358-1371.

[13] Kazis LE. The Veterans SF-36 ${ }^{\circledR}$ Health Status Questionnaire: Development and Application in the Veterans Health Administration. Medical Outcomes Trust Monitor. $2000 ; 5(1): 1-14$

[14] Miller DR, Skinner KM, Kazis LE. Study design and sampling in the Veterans Health Study. J Ambul Care Manage. 2004;27(2):166-179.

[15] Kazis LE, Miller DR, Skinner KM, et al. Patient Reported Measures of Health: The Veterans Health Study. J Ambul Care Manage. 2004a;27(1):70-83. 
[16] Kazis LE, Miller D, Clark JA, et al. Improving Response Choices of the SF-36 ${ }^{\circledR}$ Role Functioning Scales: Results from the Veterans Health Study. J Ambul Care Manage Forthcoming. 2004b.

[17] Kazis L, Ren XS, Lee A et al. Health Status in VA patients: Results from the Veterans Health Study. American Journal of Medical Quality. 1999;14(1):28-38.

[18] Kazis LE, Selim A, Rogers W, Ren XS, Lee A, Miller DR. Dissemination of methods and results from the veterans health study: final comments and implications for future monitoring strategies within and outside the veterans healthcare system. J Ambul Care Manage. 2006;29(4):310-9.

[19] Rose AJ, Sacks NC, Deshpande AP, Griffin SY, Cabral HJ, Kazis LE. Single-Change items did not measure change in quality of life. J Clin Epidemiol. 2008;61:603-608.

[20] Helmer DA, Chandler HK, Quigley KS, Blatt M, Teichmann R, Lange G. Chronic Widespread Pain, Mental Health, and Physical Role Function in OEF/OIF Veterans. Pain Med. 2009;10(7):1174-1182.

[21] Turner AP, Kivlahan DR, Haselkorn JK. Exercise and quality of life among people with multiple sclerosis: looking beyond physical functioning to mental health and participation in life. Arch Phys Med Rehabil. 2009;90(3):420-8.

[22] Goldberg J, Magruder KM, Forsberg CW, Kazis LE et al. The association of PTSD with physical and mental health functioning and disability (VA Cooperative Study \#569: the course and consequences of posttraumatic stress disorder in Vietnam-era Veteran twins. Qual Life Res. 2014;23:1579-1591.

[23] Selim AJ, Rogers W, Fleishman JA, Qian SX, Fincke BG, Rothendler JA, Kazis LE. Updated U.S. population standard for the Veterans RAND 12-item Health Survey (VR-12). Qual Life Res. 2009;18:43-52. 
[24] Denneson LM, Lasarev MR, Dickinson KC, Dobscha SK. Alcohol Consumption and Health Status in Vey Old Veterans. J Geriatric Psychiatry and Neurology. 2011;24(1):39-43.

[25] Fang SC, Schnurr PP, Kulish AL, Holowka DW, Marx BP, Keane TM, Rosen R. Psychosocial Functioning and Health-Related Quality of Life Associated with Posttraumatic Stress Disorder in Male and Female Iraq and Afghanistan War Veterans: The VALOR Registry. J Womens Health (Larchmt). 2015;24(12):1038-1046.

[26] Kwon JY, Sawatzky R. Examining gender-related differential item functioning of the Veterans Rand 12-item Health Survey. Qual Life Res. 2017;26(10):2877-2883.

[27] Ding K, Slate M, Yang J. History of co-occuring disorders and current mental health status among homeless veterans. BMC Public Health. 2018;18(1):751.

[28 ] Bottone FG Jr, Hawkins K, Musich S, Cheng Y, Ozminkowski RJ, Migilori RJ, Yeh CS. The relationship between body mass index and quality of life in community-living older adults living in the United States. J Nutr Health Aging. 2013;17(6):495-501.

[29] Werner BC, Hadeed MM, Gwalthmey FW Jr, Gaskin CM, Hart JM, Miller MD. Medical injury in knee dislocations: what are the common injury patterns and surgical outcomes? Clin Orthop Relat Res. 2014;472(9):2658-2666.

[30] Schalet BD, Rothrock NE, Hays RD, Kazis LE, Cook KF, Rutsohn JP, Cella D. Linking Physical and Mental Health Summary Scores from the Veterans RAND 12-Item Health Survey (VR-12) to the PROMIS ${ }^{\circledR}$ Global Health Scale. J Gen Intern Med. 2015;30(10):1524-1530. [31] Oak SR, Strnad GJ, Bena J, Farrow LD et al. Responsiveness Comparison of the EQ-5D, PROMIS Global Health, and VR-12 Questionnaires in Knee Arthroscopy. Orthop J Sports Med. 2016;4(12):1-7. 
559

560

561

562

563

564

565

566

567

568

569

570

571

572

573

574

575

576

577

578

579

580

581

[32] Doll KM, Pinheiro LC, Reeve BB. Pre-diagnosis health-related quality of life, surgery, and survival in women with advanced epithelial overian cancer: A SEER-MHOS study. Gynecol

Oncol. 2017;144(2):348-353.

[33] George J, Newman JM, Caravella JW, Klika AK, Barsoum WK, Hiquera CA. Predicting Functional Outcomes After Above Knee Amputation for Infected Total Knee Arthroplasty. J Arthroplasty. 2017;32(2):532-6.

[34] Solberg MJ, Algueza AB, Hunt TJ, Higgins LD. Predicting 1-Year postoperative visual analog scale pail scores and American shoulder and elbow surgeons function scores in total and reverse total shoulder arthroplasty. Am J Orthop (Belle Mead NJ). 2017;46(6):E358E365.

[35] Gornet MF, Copay AG, Sorensen KM, Schranck FW. Assessment of health-related quality of life in spine treatment: conversion from SF-36 to VR-12. Spine J. 2018;18(7):1292-7.

[36] Rolfson O, Eresian Chenok K, Bohm E et al. Patient-reported outcome measures in arthroplasty registries. Acta Orthop 2016;87 Suppl 1:3-8.

[37] Kazis LE, Selim AJ, Rogers W, Qian SX, Brazier J. Monitoring Outcomes for the Medicare Advantage Program. Methods and Application of the VR-12 for Evaluation of Plans. J Ambul Care Manage. 2012;35(4):263-276.

[38] Ozminkowski RJ, Musich S, Bottone FG Jr, Hwakins K, Bai M, Unützer J, Hommer CE, Migliori RJ, Yeh CS. The burden of depressive symptoms and various chronic conditions and health concerns on the quality of life among those with Medicare Supplement Insurance. Int J Geriatr Psychiatry. 2012;27(9):948-958.

[39] Bullinger M. German translation and psychometric testing of the SF-36 Health Survey: Preliminary Results from the IQOLA project. Soc Sci Med. 1995;41(10):1359-1366. 
582

583

584

585

586

587

588

589

590

591

592

593

594

595

596

597

598

599

600

601

602

603

604

605

[40] Bullinger M, Alonso J, Apolone $G$, Lepège A, Sullivan M, Wood-Dauphinee S, Gandek B,

Wagner A, Aaronson N, Bech P, Fukuhara S, Kaasa S, Ware JE, for the IQOLA Project Group.

Translating Health Status Questionnaires and Evaluating Their Quality: The IQOLA Project

Approach. J Clin Epidemiol. 1998;51(11):913-923.

[41] [Muthny FA, Bullinger M, Kohlmann T. Variablen und Erhebungsinstrumente in der

rehabilitationswissenschaftlichen Forschung - Würdigung und Empfehlungen. In: Verband

Deutscher Rentenversicherungsträger, editor. Empfehlungen der Arbeitsgruppen

„Generische Methoden“, „Routinedaten“ und „Reha-Ökonomie“. DRV-Schriften. 1999;16:54-

61.]

[42] [Zwingmann C, Moock J, Kohlmann T. Instruments for Patient-Reported Outcomes and

Predictors in German Rehabilitation Research - Current Developments within the

„Rehabilitation Sciences” Research Funding Programme. Rehabilitation. 2005;44:e57-e68.]

[43] Morfeld M, Bullinger M, Nantke J, Brähler M. The version 2.0 of the SF-36 Health Survey:

results of a population- representative study. Soz-Präventivmed. 2005;50:292-300.

https://doi.org/10.1007/s00038-005-4090-6

[44] Brooks R. EuroQol: the current state of play. Health Policy. 1996;37(1):53-72.

[45] Herdman M, Gudex C, Lloyd A, Janssen MF, Kind P, Parkin D, Bonsel G, Badia X.

Development and preliminary testing of the new five-level version of EQ-5D (EQ-5D-5L).

Quality Life Res. 2011;20(10):1727-1736.

[46] Janssen MF, Pickard AS, Golicki D, Gudex C, Niewada M, Scalone L, Swinburn P,

Busschbach J. Measurement properties of the EQ-5D-5L compared to the EQ-5D-3L across

eight patient groups: a multi-country study. Qual Life Res. 2013;22(7):1717-1727.

[47] Ludwig K, Graf von der Schulenburg J-M, Greiner W. German Value Set for the EQ-5D-

5L. PharmacoEconomics. 2018;36(6):663-674. 
606

607

608

609

610

611

612

613

614

615

616

617

618

619

620

621

622

623

624

625

626

627

[48] Centers for Disease Control and Prevention. Measuring Healthy Days. Atlanta, Georgia:

CDC; 2000.

[49] Slabaugh SL, Shah M, Zack M, Happe L, Cordier T, Havens E, Davidson E, Miao M, Prewitt T, Jia H. Leveraging Health-Related Quality of Life in Population Health Management: The Case for Healthy Days. Popul Health Manag. 2017;20(1):13-22.

[50] [Kohlmann T, Raspe HH. The Hannover Functional Ability Questionnaire for Measuring Back Pain-Related Functional Limitations (FFbH-R). Rehabilitation. 1996;35:1-8.]

[51] [Lautenschläger J, Mau W, Kohlmann T, Raspe HH, Struve F, Brückle W, Zeidler H.

Comparative evaluation of a German version of the Health Assessment Questionnaire (HAQ) and the Hannover Functional Ability Questionnaire (HFAQ). Z Rheumatol. 1997;56:144-155.]

[52] [Haase I, Schwarz A, Burger A , Kladny B. Comparison of Hannover Functional Ability

Questionnaire (FFbH) and the SF-36 scale "Physical Functioning". Rehabilitation.

2001;40(1):40-2.]

[53] [Nilges P Essau C. Depression, anxiety and stress scales: DASS--A screening procedure not only for pain patients. Schmerz. 2015;29(6):649-657.]

[54] Lovibond SH, Lovibond PF. Depression Anxiety and Stress Scales (Instruments for Adults). 1995. [DASS]. In: Fischer J, Corcoran K, editors. Measures for clinical practice and research: a sourcebook. 4th ed. Vol 2. New York: Oxford University Press; 2007. p. 219-221. [55] Von Korff M, Ormel J, Keefe FJ, Dworkin SF. Grading the severity of chronic pain. Pain. 1992;50:133-149.

[56] Von Korff M, Deyo RA et al. Back pain in primary care. Spine. 1993;18:855-862. (Table 1 page 856). 
[57] [Deck R, Muche-Borowski C, Mittag O et al. IMET - Index zur Messung von

Einschränkungen der Teilhabe. In: Bengel J, Wirtz M, Zwingmann C, editors. Diagnostische Verfahren in der Rehabilitation. Göttingen: Hogrefe; 2008. p. 372-374.]

[58] [Deck R, Walter AL, Staupendahl A, Katalinic A. Limitations of Social Participation in General Population - Normative Data of the IMET based on a Population-Based Survey in Northern Germany. Rehabilitation. 2015;56(4):402-408.]

[59] [Gerdes N, Jäckel WH. Indicators of Reha Status (IRES)" A Patient Questionnaire for Assessing Rehabilitation Need and Outcome. Rehabilitation. 1992;31(2):73-9.]

[60] Kazis LE, Lee A, Spiro III. A, Rogers W, Ren XS, Miller DR, Selim A, Hamed A, Haffer SC. Measurement Comparisons of the Medical Outcomes Study and the Veterans SF- $36^{\circledR}$ Health Survey Health Care Financing Review. 2004c;25(4):43-58.

[61] Kazis LE, Miller DR, Clark JA, Skinner KM, Lee A, Ren XS, Spiro III. A, Rogers WH, Ware Jr. JE. Improving the response choices on the veterans SF-36 health survey role functioning scales: results from the Veterans Health Study. J Ambul Care Manage. 2004d;27(3):263-280. [62] Rogers WH, Qian S, Kazis L. Imputing the physical and mental summary scores (PCS and MCS) for the MOS SF-36 and the Veterans SF-36 Health Survey in the presence of Missing Data. Updated and completed Technical Report. 2004. http://citeseerx.ist.psu.edu/viewdoc/download;jsessionid=81CCD7D11E2A92DFEF72707C274F2677? doi=10.1.1.556.5284\&rep=rep1\&type=pdf (last accessed 6-15-20) [63] Lenhard W, Lenhard A (2014). Significance tests for correlations. Available at: https://www.psychometrica.de/korrelation.html. Bibergau: Psychometrica. DOI: 10.13140/RG.2.1.2954.1367 Assessed 15 Oct 2020.

[64] Beaton DE, Bombardier C, Katz JN, Wright JG. A taxonomy for responsiveness. J Clin Epidemiol. 2001;54(12):1204-1217. 
652

653

654

655

656

657

658

659

660

661

662

663

664

665

666

667

668

669

670

671

672

673

674

675

[65] Boston University School of Public Health Site. Request access to the VR-instruments.

http://www.bu.edu/sph/about/departments/health-law-policy-and-

management/research/vr-36-vr-12-and-vr-6d/request- access/ Accessed 17 Sept 2018.

[66] Boston University School of Public Health Site. References of the VR-instruments by

year. https://www.bu.edu/sph/about/departments/health-law-policy-and-

management/research/vr-36-vr-12-and-vr-6d/resources/references/ Accessed 16 Mar 2019.

[67] Kronzer VL, Jerry MR, Abdallah AB, Wildes TS, McKinnon SL, Sharma A, Avidan MS.

Changes in quality of life after elective surgery: an observational study comparing two measures. Qual Life Res. 2017; 26(8):2093-2102.

[68] Levy CE, Silverman E, Jia H, Geiss M, Omura D. Effects of physical therapy delivery via home video telerehabilitation on functional and health-related quality of life outcomes. J

Rehabil Res Dev. 2015;52(3):361-70.

[69] Bedigrew KM, Patzkowski JC, Wilken JM, Owens JG, Blanck RV, Stinner D.J et al. Can an Integrated Orthotic and Rehabilitation Program Decrease Pain and Improve Function After Lower Extremity Trauma? Clin Orthop Relat Res. 2014;472(10):3017-3025.

\section{ADDITIONAL FILES}

\section{Additional file 1}

Title of data: Key differences between the original English and the German Translated VR-36

Description of data: This file provides information on the key differences between the original English VR and its German translation. It shows an extract of the translation protocol and helps the reader to identify and retrace main semantical and conceptual differences between both versions due to cultural and linguistic adaptations during the translation process. 


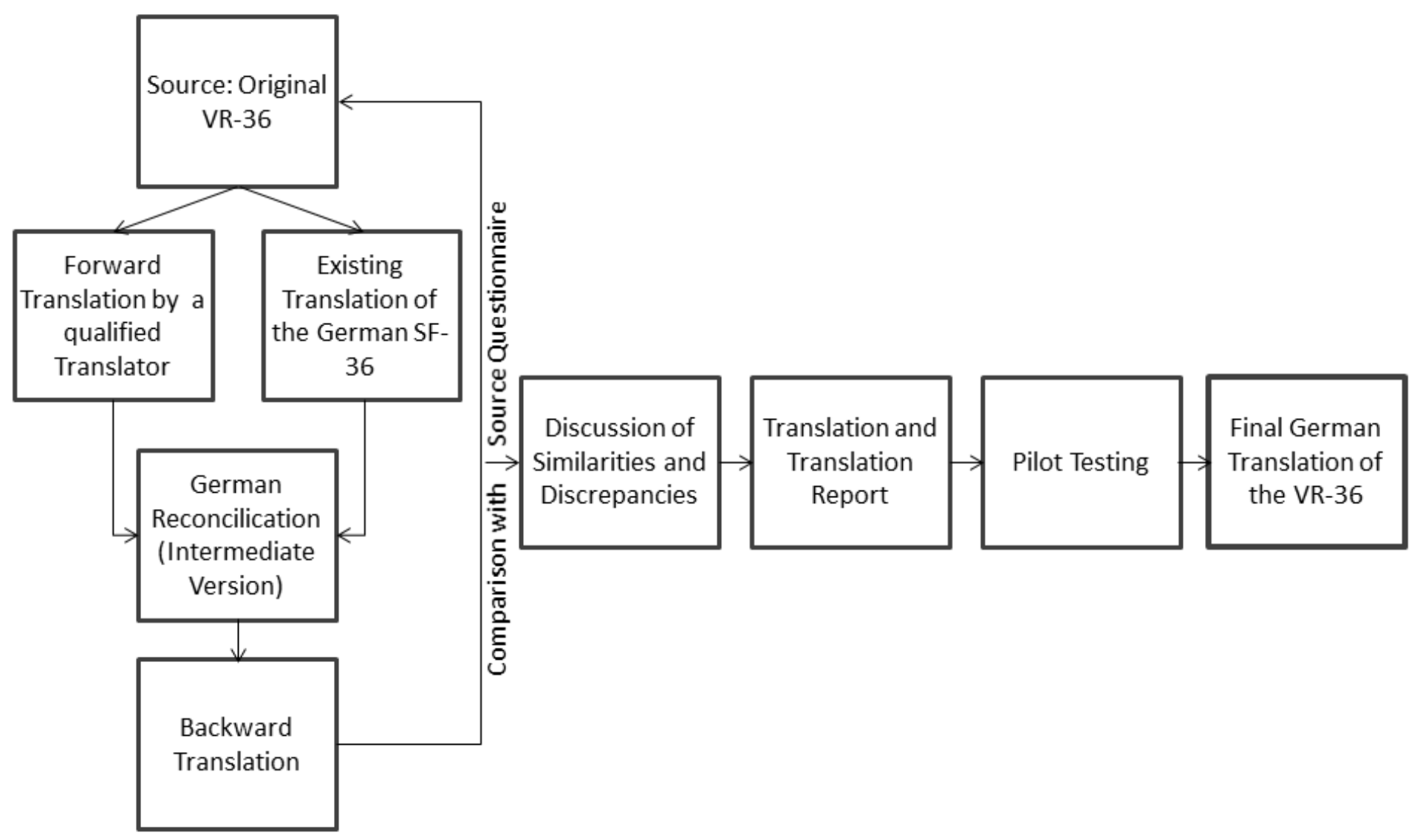

Figure 1

Flow chart of the translation process 
$n=400$ orthopedic and $n=400$ psychosomatic rehabilitation patients

\section{Randomization}

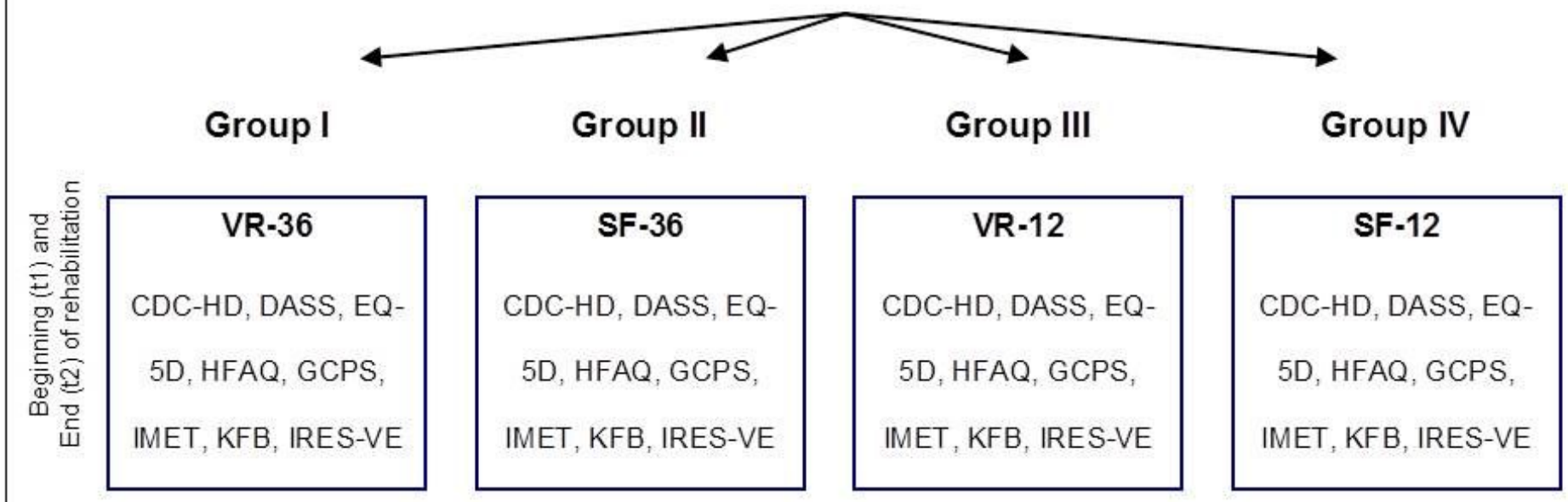

Figure 2

Survey study design
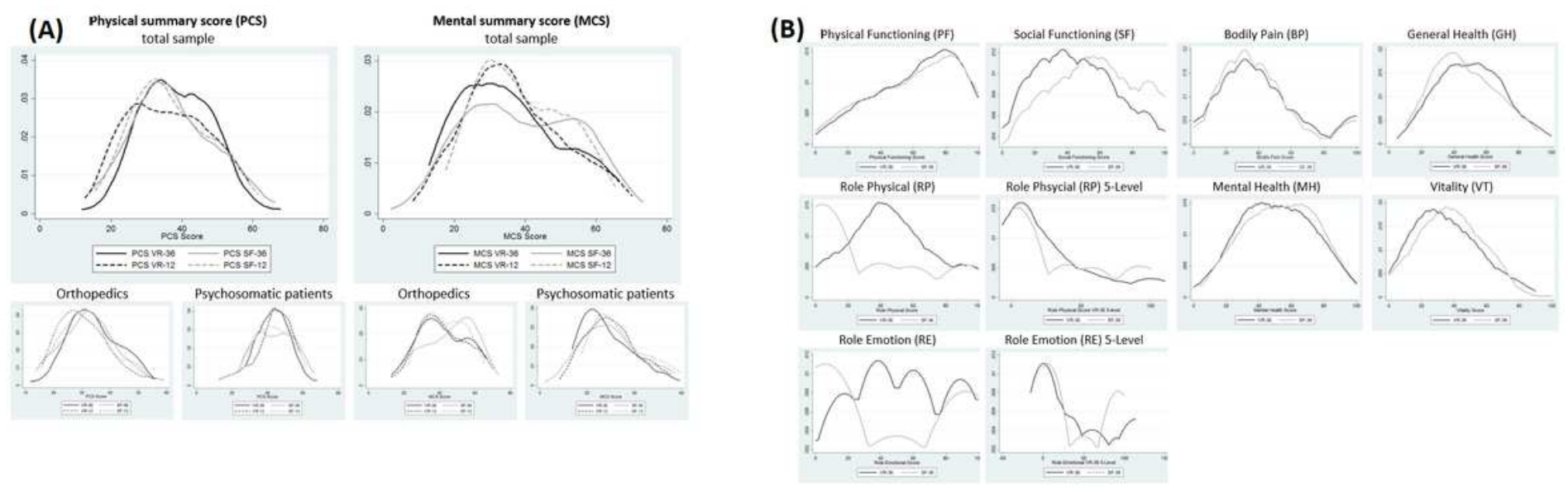

Figure 3 
A) Kernel density estimation for PCS and MCS B) Kernel plots of the scales of the VR-36 and SF-36

\section{Supplementary Files}

This is a list of supplementary files associated with this preprint. Click to download.

- Additionalfile1Keydifferencesfin.docx 